until such time as the hyphæ have grown some way on to, and among, the fibres of the papers. The papers are then lifted carefully, carrying with them a quantity of the growing mycelium embedded among the fibres, and transferred to the liquid for soaking. The slips of paper can afterwards be washed and laid flat on the surface of a medium and incubated to observe growth.

Use of this method ensures that, as the spores or mycelium are embedded in the fibres of the paper, there is complete contact with the liquid they are immersed in, and small particles are not shielded from it by bubbles of air. 'The texture of the paper used can be varied according to the spore size of the fungus which is being tested.

Department of Mycology, University, Edinburgh. Nov. 2.

\section{Susceptibility of Solanum curtilobum to Spongospora subterranea (Wallr.) Johnson}

IT has been stated by Dorojkin ${ }^{1}$ that Solanum curtilobum and eight other South American species and varieties of Solanum are immune from Spongospora subterranea, the causal agent of powdery scab of potatoes ; in this paper the number 8008 is linked with $S$. curtilobum, as are other numbers with the other Solanum species, and these are presumably the reference numbers of individual lines which were being used. Bukasov ${ }^{2}$ quotes Dorojkin and states that immunity from powdery scab has been established in S. curtilobum and the eight other species and varieties. This statement has been repeated by Hawkes ${ }^{3}$ and Black $^{4}$, but in these papers no mention is made of the reference numbers of the individual lines concerned. It might be assumed, therefore, that $S$. curtilobum as such is immune, despite the fact that many lines or varieties of this species exist. That some of these lines at least do not carry immunity was shown by the following experiments.

In the 1948 and 1950 seasons several lines of S. curtilobum were tested at this Station, together with a number of commercial varieties of $S$. tuberosum, for susceptibility to powdery scab. The method adopted was as follows: sterilized soil was inoculated with spore balls of $S$. subterranea collected from a large quantity of affected tubers. After addition of an adequate amount of a complete fertilizer, ground shell lime was added in an amount calculated to bring the $p \mathrm{H}$ of the soil to $7 \cdot 2$, since it had been found, in previous experiments, that at this $p H$ excellent infection of susceptible varieties was obtained. Pots were filled with this soil, which was, thereafter, kept as far as possible at a moisture content of about 85 per cent of its field capacity either by daily watering and periodical check-weighing or by standing the pots in shallow pans of water. Tubers of the varieties to be tested were surface sterilized in 2 per cent formalin prior to planting in this soil.

In 1948, two plants of one line (Commonwealth Potato Collection No. 2192) of S. curtilobum were grown. One of the plants was examined when the haulm had completely died down and the root system had disintegrated. Only a few small tubers were produced and these were free from infection. Examination of the roots and stolons of the other plant at an earlier stage, however, revealed numerous nodules of proliferated tissue bearing masses of $S$. subterranea spore balls in many stages of development. In parallel tests with the commercial variety Epicure, many nodules were observed on the roots of the plant lifted before maturity, while the tubers produced by the plant which was allowed to mature were fairly severely affected, bearing on the average 23 pustules per tuber.

The experiment was repeated in 1950 using three other lines of S. curtilobum (CPC. 221, 247, 2191) as well as CPC 2192, which was tested previously. Conditions in this experiment were unfortunately not ideal for infection, and the tubers of the Epicure control plants were only slightly attacked. It is not surprising, therefore, that no pustules were observed on any of the $S$. curtilobum tubers. In two of the lines, CPC 2191 and 2192 , however, nodules bearing $S$. subterranea spore balls were again observed on the stolons.

It is concluded that although immunity from $S$. subterranea may exist within the species $S$. curtilobum, certain lines are susceptible, at least in the stolons and roots. S. curtilobum as such, with no reference to particular lines, cannot therefore be claimed as immune from powdery scab. It would be unusual to find tuber immunity associated with stolon susceptibility; but to come to some definite conclusion on this point, more severe conditions of experimental infection would be necessary than those obtaining in the above tests.

Thanks are due to Dr. J. C. Haigh for supplying the $S$. curtilobum lines which were tested.

$$
\text { A. E. W. Boyd }
$$

Department of Agriculture for Scotland, Plant Pathology Laboratory, East Craigs, Corstorphine, Edinburgh. Sept. 30.

1 Dorojkin, N. A., in "Powdery Scab of Potatoes", White Russ. Acad. Sci., Inst. Biol. Sci., Minsk, 5 (1936). 2 Bukasov, S. M., Physis. B. Aires., 18, 41 (1939).

${ }^{3}$ Hawkes, J. G., Emp. J. Exp. Agric., 13, No. 49, 11 (1945).

‘ Black, W., Farming (Norwich), 1, 327 (1947).

\section{Echoes from the $D$ - and $F_{2}$-Layers on a Frequency of 2l Mc./s.?}

DURING the month of November and up to the time of writing (December 20), we noticed, while we were sending out pulses on a frequency of $26 \mathrm{Mc} / \mathrm{s}$., an unknown station was apparently sending pulses on a frequency of about $21.7 \mathrm{Mc}$./s. The station appeared to be rather distant, as the ground wave (?) received was fading very badly at times. As we do not know the location of this station, we think it may be interesting for ionosphere workers to know of the reception of these pulses at Macau Observatory.

The pulse covered about $10 \mathrm{~km}$. on our display. Most of the time, at a virtual height of about $40-50 \mathrm{~km}$., there were shown echoes of varying intensities, and often double echoes. These $D$ (?)-layer echoes sornetimes remained strong, while the pulse itself was almost reduced to zero by the fading. Sometimes these $D$-echoes were absent during several minutes, only to show again with this intermittent period.

More rarely, another weak to very strong pulse or echo was noticed at a virtual height of $400-500 \mathrm{~km}$. It may have been simply the reception of the pulse having gone round the world; but we would rather regard this echo as an $F_{2^{-}}$or $G$-layer echo.

The time of emission of these pulses was regularly from 09 until 12h. G.M.T.

ZiKaWei Observatory; E. Gherzi, S.J. now at the Macau Observatory. 